\section{Research Square}

Preprints are preliminary reports that have not undergone peer review.

They should not be considered conclusive, used to inform clinical practice, or referenced by the media as validated information.

\title{
Burden of Chronic Kidney Disease and Its Risk-Attributable Burden in 137 Low-and Middle-Income Countries, 1990-2019: Results From The Global Burden of Disease Study 2019
}

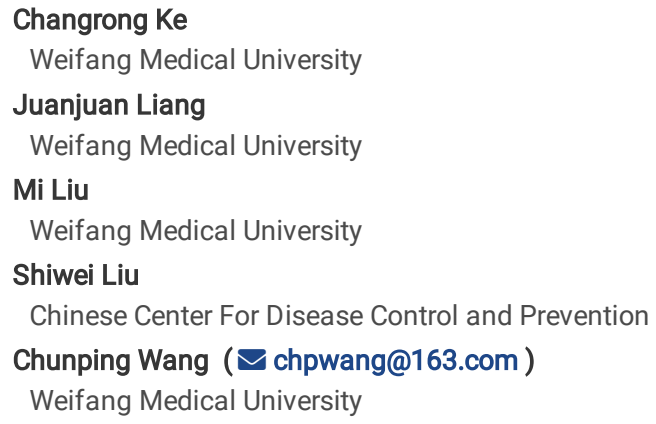

Version of Record: A version of this preprint was published at BMC Nephrology on January 5th, 2022. See the published version at https://doi.org/10.1186/s12882-021-02597-3. 


\section{Abstract \\ Background}

Chronic kidney disease (CKD) is a global public health concern, but its disease burden and risk-attributable burden in CKD has been poorly studied in low - and middle-income countries (LMICs). This study aimed to estimate CKD burden and risk-attributable burden in LMICs from 1990 to 2019.

\section{Methods}

Data were collected from the Global Burden of Disease (GBD) Study 2019, which measure CKD burden using the years lived with disability (YLDs), years of life lost (YLLs), disability-adjusted life-years (DALYs) and estimate risk-attributable burden using population-attributable faction (PAF) from 1990 to 2019 . The 95\% uncertainty intervals (Uls) were calculated and reported for YLDs, YLLs and DALYs.

\section{Results}

In 2019, the age-standardized YLL rate is much higher than the YLD rate in various income regions. LICs had the highest age-standardized DALY rate at 692.25 per 100,000 people (95\%Ul: 605.14 to 785.67), followed by Lower MICs. From 1990 to 2019, the age-standardized DALY rate showed a 13.70\% reduction in LICs, 2.25\% reduction Upper MICs but 3.72\% rising in Lower MICs. Age-standardized YLD rate was higher in females than in males, whereas age-standardized rates of YLL and DALY of CKD were all higher in males than in females in globally and various income regions. Additionally, there were upward trends in the CKD-related age-specific YLD, YLL and DALY rates in various income regions. In 2019, kidney dysfunction, high systolic blood pressure, high fasting plasma glucose, and high body-mass index remained the major causes attributable age-standardized CKD DALYs. From 1990 to 2019 , there were upward trends in the PAF contributions of high fasting plasma glucose, high systolic blood pressure, and high body-mass index. The greatest increase in the PAF was high bodymass index, especially in Lower MICs.

\section{Conclusions}

CKD burden remains high in various income regions, especially in MICs and Lower MICs. More effective and targeted preventive policies and interventions aimed at mitigating preventable CKD burden and addressing risk factors are urgently needed, particularly in geographies with high or increasing burden.

\section{Introduction}

Chronic kidney disease (CKD) is a global public health concern[1], and a risk factor for adverse outcomes in other diseases[2, 3]. The global burden of CKD is rapidly increasing and is projected to become the 5th most common cause of years of life lost worldwide by 2040[4,5], with the burden of CKD increasing faster in low - and middle-income countries (LMICs)[6]. The burden of CKD is studied predominantly in high-income countries, with few studies in LMICs, and even fewer studies on attributable disease burden[2]. In this study, we aimed to analyzed and compared the trends of disease burden of CKD as well as its attributable disease burden in LMICs from 1990 to 2019, by using the data from the GBD 2019 study.

\section{Methods \\ Data sources}

Data for this study were obtained from the GBD 2019 study. The GBD 2019 provides estimates of years lived with disability (YLDs), years of life lost (YLLs), and disability-adjusted life-years (DALYs) disaggregated due to 369 diseases and injuries, and 87 risk factors and combinations of risk factors in 204 countries and territories from 1990 to 2019[7, 8]. Detailed methods of GBD 2019 have been published elsewhere[7, 8]. The GBD 2019 attributable burden estimates followed the general framework established for comparative risk assessment (CRA) [9, 10]. Compared with previous GBD studies[11-13], the GBD 2019 study developed new approaches to estimate risk exposure and risk-attributable burden by integrating all accessible data from multiple epidemiological studies in various countries[7]. These studies included high-quality systematic reviews, cohorts, trials, case-control studies and other observational studies[7].

This study adherence to the Guidelines for Accurate and Transparent Health Estimates Reporting (GATHER) recommendations[14]. All data used in this study were obtained from the Institute for Health Metrics and Evaluation (IHME) website[15].

In the GBD study, chronic kidney disease was recognized as a disease as well as a metabolic risk factor[16]. In this analysis, we treated chronic kidney disease as a disease. CKD was defined as eGFR(estimated glomerular filtration rate) of $<60 \mathrm{~mL} / \mathrm{min}$ per $1.73 \mathrm{~m}^{2}[16]$.

\section{Definitions}

We used years lived with disability (YLDs), years of life lost (YLLs) and disability-adjusted life-years (DALYs) to measure the burden caused by CKD. YLDs measures the amount of time people lose to diseases and injuries that degrade their level of health but do not cause death. YLLs is a measure of premature death within a group of people. DALYS is a comprehensive index to evaluate the disease burden of disability and premature death, it is calculated by adding the YLLs and the YLDs[17, 18]. 
Due to the potential effects of climate change on human health, two new risk factors (high and low non-optimal temperatures) have been added in GBD 2019. 8 risk factors, i.e. high temperature, low temperature, Lead exposure, diet high in sodium, high systolic blood pressure, high fasting plasma glucose, high body mass index, impaired kidney function, were considered to be associated with CKD In GBD 2019.

In our analyses we classified countries according to World Bank Income Levels in 2019, a total of 137 low-and middle-income countries (LMICs) were categorized into three groups: 31 low-income countries (LICs), 47 lower-middle income countries (Lower MICs) and 59 upper-middle income countries (Upper MICs).

\section{Statistical analyses}

We computed counts, and age-standardized rates (per 100 000) to quantify the burden of CKD. YLDs, YLLs and DALYs were metrics used to measure the burden of CKD and reported by specific region, year, sex, age. Age-standardized rates (per 100 000) were standardized by the global age-standard population. The percentage contributions of risk factors to age-standardized CKD DALYs were calculated by the population attributable fraction (PAF).

\section{Uncertainty interval}

For each estimated rate and number of YLDs, YLLs, DALYs, and PAF of risk-attributable CKD DALYs, we reported its $95 \%$ uncertainty interval (UI). 95\% UI was calculated by taking 1000 draws from the posterior distribution of each quantity and using the 25th and 975 th-ordered draw of the uncertainty distribution[19].

\section{Results}

There were upward trends in the CKD-related YLDs, YLLs and DALYs in various income regions from 1990 to 2019 (Table 1). In 2019, the age-standardized YLL rate is much higher than the YLD rate at the global level and in various income regions. LICs had the highest age-standardized DALY rate at 692.25 per 100,000 people (95\%Ul: 605.14 to 785.67) in 2019, followed by Lower MICs, while Upper MICs had the lowest rate. From 1990 to 2019 , the age-standardized YLD rate all showed an upward trend in various income regions, while YLL rate decreased in LICs, Upper MICs and demonstrated a minor increase trend in Lower MICs. The age-standardized DALY rate showed a 13.70\% reduction in LICs, $2.25 \%$ reduction in Upper MICs, whereas increased $3.72 \%$ from 660.14 (95\%Ul: 601.55 to 723.28 ) in 1990 to $684.72(95 \%$ Ul: 623.56 to 746.12 ) in 2019 in Lower MICs. (Table 2). 
Table 1

Number of YLDs, YLLs, DALYs of CKD with percent change in specific region, 1990-2019

\begin{tabular}{|c|c|c|c|c|c|c|c|c|}
\hline \multirow[t]{2}{*}{ region } & \multicolumn{3}{|l|}{$\begin{array}{l}\text { YLDs } \\
\text { (in thousands) }\end{array}$} & \multicolumn{3}{|l|}{$\begin{array}{l}\text { YLLs } \\
\text { (in thousands) }\end{array}$} & \multicolumn{2}{|l|}{$\begin{array}{l}\text { DALYs } \\
\text { (in thousands) }\end{array}$} \\
\hline & 1990 & 2019 & $\begin{array}{l}\% \\
\text { change }\end{array}$ & 1990 & 2019 & $\begin{array}{l}\% \\
\text { change }\end{array}$ & 1990 & 2019 \\
\hline \multicolumn{9}{|l|}{ Global } \\
\hline Male & $\begin{array}{l}1741.00(1257.88 \\
\text { to } 2303.57)\end{array}$ & $\begin{array}{l}4021.93(2903.65 \\
\text { to } 5335.61)\end{array}$ & 131.01 & $\begin{array}{l}9459.51(8850.56 \text { to } \\
10238.32)\end{array}$ & $\begin{array}{l}17958.18(16654.70 \\
\text { to } 19565.50)\end{array}$ & 89.84 & $\begin{array}{l}11200.51(10402.02 \\
\text { to } 12151.42)\end{array}$ & $\begin{array}{l}21980.11\left(20^{\circ}\right. \\
\text { to } 23965.10)\end{array}$ \\
\hline Female & $\begin{array}{l}2136.55(1543.68 \\
\text { to } 2754.34)\end{array}$ & $\begin{array}{l}4724.57(3429.29 \\
\text { to } 6179.89)\end{array}$ & 121.13 & $\begin{array}{l}8167.50(7550.21 \text { to } \\
8778.44)\end{array}$ & $\begin{array}{l}14833.90(13467.77 \\
\text { to } 16117.36)\end{array}$ & 81.62 & $\begin{array}{l}10304.06(9457.91 \\
\text { to } 11216.13)\end{array}$ & $\begin{array}{l}19558.48(17 k \\
\text { to } 21467.98)\end{array}$ \\
\hline Both & $\begin{array}{l}3877.55(2790.33 \\
\text { to } 5063.93)\end{array}$ & $\begin{array}{l}8746.51(6320.23 \\
\text { to } 11508.24)\end{array}$ & 125.57 & $\begin{array}{l}17627.02(16596.25 \\
\text { to } 18589.76)\end{array}$ & $\begin{array}{l}32792.08(30450.91 \\
\text { to } 35049.54)\end{array}$ & 86.03 & $\begin{array}{l}21504.57(20039.12 \\
\text { to } 23065.78)\end{array}$ & $\begin{array}{l}41538.59(38: \\
\text { to } 45037.86)\end{array}$ \\
\hline \multicolumn{9}{|l|}{ LICs } \\
\hline Male & $\begin{array}{l}64.78(45.86 \text { to } \\
86.48)\end{array}$ & $\begin{array}{l}183.03(128.83 \text { to } \\
243.54)\end{array}$ & 182.56 & $\begin{array}{l}812.62(705.35 \text { to } \\
915.27)\end{array}$ & $\begin{array}{l}1374.18(1155.57 \text { to } \\
1633.83)\end{array}$ & 69.11 & $\begin{array}{l}877.40(771.03 \text { to } \\
981.89)\end{array}$ & $\begin{array}{l}1557.22(132 \\
1816.35)\end{array}$ \\
\hline Female & $\begin{array}{l}86.82(62.37 \text { to } \\
114.16)\end{array}$ & $\begin{array}{l}236.24(170.14 \text { to } \\
308.59)\end{array}$ & 172.11 & $\begin{array}{l}725.37(579.46 \text { to } \\
886.26)\end{array}$ & $\begin{array}{l}1123.96(956.11 \text { to } \\
1317.79)\end{array}$ & 54.95 & $\begin{array}{l}812.19(666.47 \text { to } \\
978.52)\end{array}$ & $\begin{array}{l}1360.20(116\{ \\
1567.74)\end{array}$ \\
\hline Both & $\begin{array}{l}151.60(108.49 \text { to } \\
199.48)\end{array}$ & $\begin{array}{l}419.28(301.72 \text { to } \\
551.00)\end{array}$ & 176.58 & $\begin{array}{l}1537.99(1323.56 \text { to } \\
1736.06)\end{array}$ & $\begin{array}{l}2498.14(2131.37 \text { to } \\
2923.69)\end{array}$ & 62.43 & $\begin{array}{l}1689.59(1467.73 \text { to } \\
1895.09)\end{array}$ & $\begin{array}{l}2917.41\left(251^{\circ}\right. \\
3337.37)\end{array}$ \\
\hline \multicolumn{9}{|l|}{$\begin{array}{l}\text { Lower } \\
\text { MICs }\end{array}$} \\
\hline Male & $\begin{array}{l}582.07(412.90 \text { to } \\
764.46)\end{array}$ & $\begin{array}{l}1435.35(1022.53 \\
\text { to } 1884.88)\end{array}$ & 146.59 & $\begin{array}{l}4102.25(3652.28 \text { to } \\
4877.33)\end{array}$ & $\begin{array}{l}8296.79(7396.62 \text { to } \\
9441.35)\end{array}$ & 102.25 & $\begin{array}{l}4684.32(4232.22 \text { to } \\
5461.27)\end{array}$ & $\begin{array}{l}9732.14(872: \\
10944.03)\end{array}$ \\
\hline Female & $\begin{array}{l}679.46(485.04 \text { to } \\
888.82)\end{array}$ & $\begin{array}{l}1716.13(1227.10 \\
\text { to } 2237.84)\end{array}$ & 152.57 & $\begin{array}{l}3402.13(2905.25 \text { to } \\
3892.33)\end{array}$ & $\begin{array}{l}6549.77(5624.24 \text { to } \\
7307.56)\end{array}$ & 92.52 & $\begin{array}{l}4081.59(3548.37 \text { to } \\
4611.32)\end{array}$ & $\begin{array}{l}8265.90\left(726^{\circ}\right. \\
9217.41)\end{array}$ \\
\hline Both & $\begin{array}{l}1261.53(894.56 \\
\text { to } 1645.02)\end{array}$ & $\begin{array}{l}3151.48(2258.15 \\
\text { to } 4109.39)\end{array}$ & 149.81 & $\begin{array}{l}7504.37(6712.65 \text { to } \\
8256.48)\end{array}$ & $\begin{array}{l}14846.56(13448.78 \\
\text { to } 16241.31)\end{array}$ & 97.84 & $\begin{array}{l}8765.91(7935.09 \text { to } \\
9641.47)\end{array}$ & $\begin{array}{l}\text { 17998.04(16: } \\
\text { to } 19659.97)\end{array}$ \\
\hline \multicolumn{9}{|l|}{$\begin{array}{l}\text { Upper } \\
\text { MICs }\end{array}$} \\
\hline Male & $\begin{array}{l}682.27(491.68 \text { to } \\
914.77)\end{array}$ & $\begin{array}{l}1586.01(1117.03 \\
\text { to } 2119.58)\end{array}$ & 132.46 & $\begin{array}{l}3368.40(3075.84 \text { to } \\
3669.85)\end{array}$ & $\begin{array}{l}5897.67(5272.58 \text { to } \\
6534.90)\end{array}$ & 75.09 & $\begin{array}{l}4050.67(3687.01 \text { to } \\
4402.69)\end{array}$ & $\begin{array}{l}7483.69(675 \\
8336.16)\end{array}$ \\
\hline Female & $\begin{array}{l}871.74(631.51 \text { to } \\
1141.58)\end{array}$ & $\begin{array}{l}1884.09(1367.00 \\
\text { to } 2491.20)\end{array}$ & 116.13 & $\begin{array}{l}2941.26(2679.18 \text { to } \\
3217.92)\end{array}$ & $\begin{array}{l}4983.55(4468.38 \text { to } \\
5549.00)\end{array}$ & 69.44 & $\begin{array}{l}3813.00(3424.11 \text { to } \\
4186.28)\end{array}$ & $\begin{array}{l}6867.63(611 ! \\
7687.36)\end{array}$ \\
\hline Both & $\begin{array}{l}1554.01(1120.48 \\
\text { to } 2050.69)\end{array}$ & $\begin{array}{l}3470.10(2493.95 \\
\text { to } 4600.83)\end{array}$ & 123.30 & $\begin{array}{l}6309.66(5880.61 \text { to } \\
6755.34)\end{array}$ & $\begin{array}{l}10881.22(9964.84 \\
\text { to } 11836.99)\end{array}$ & 72.45 & $\begin{array}{l}7863.67(7212.38 \text { to } \\
8502.03)\end{array}$ & $\begin{array}{l}14351.32(13( \\
\text { to } 15772.42)\end{array}$ \\
\hline
\end{tabular}


Table 2

Age-standardized YLD, YLL and DALY rates of CKD with percent change in specific region, 1990-2019

\begin{tabular}{|c|c|c|c|c|c|c|c|c|c|}
\hline \multirow[t]{2}{*}{ region } & \multicolumn{3}{|c|}{$\begin{array}{l}\text { Age-standardized YLD rate per } 100000 \\
\text { persons }\end{array}$} & \multicolumn{3}{|c|}{$\begin{array}{l}\text { Age-standardized YLL rate per } 100000 \\
\text { persons }\end{array}$} & \multicolumn{3}{|c|}{$\begin{array}{l}\text { Age-standardized DALY rate per } 100000 \\
\text { persons }\end{array}$} \\
\hline & 1990 & 2019 & $\begin{array}{l}\% \\
\text { change }\end{array}$ & 1990 & 2019 & $\begin{array}{l}\% \\
\text { change }\end{array}$ & 1990 & 2019 & $\begin{array}{l}\% \\
\text { change }\end{array}$ \\
\hline \multicolumn{10}{|l|}{ Global } \\
\hline Male & $\begin{array}{l}83.06(60.14 \text { to } \\
108.94)\end{array}$ & $\begin{array}{l}104.03(75.56 \\
\text { to } 137.05)\end{array}$ & 25.25 & $\begin{array}{l}454.55(426.04 \\
\text { to } 488.90)\end{array}$ & $\begin{array}{l}470.20(435.54 \\
\text { to } 510.93)\end{array}$ & 3.44 & $\begin{array}{l}537.61(499.52 \\
\text { to } 580.01)\end{array}$ & $\begin{array}{l}574.23(527.52 \\
\text { to } 625.27)\end{array}$ & 6.81 \\
\hline Female & $\begin{array}{l}91.65(66.14 \text { to } \\
118.85)\end{array}$ & $\begin{array}{l}113.13(81.95 \\
\text { to } 147.68)\end{array}$ & 23.44 & $\begin{array}{l}352.04(328.69 \\
\text { to } 377.34)\end{array}$ & $\begin{array}{l}350.49(318.55 \\
\text { to } 380.64)\end{array}$ & -0.44 & $\begin{array}{l}443.69(409.36 \\
\text { to } 481.56)\end{array}$ & $\begin{array}{l}463.61(419.34 \\
\text { to } 509.95)\end{array}$ & 4.49 \\
\hline Both & $\begin{array}{l}87.22(63.28 \text { to } \\
113.54)\end{array}$ & $\begin{array}{l}108.40(78.51 \\
\text { to } 142.56)\end{array}$ & 24.29 & $\begin{array}{l}397.25(375.73 \\
\text { to } 417.52)\end{array}$ & $\begin{array}{l}406.46(377.87 \\
\text { to } 434.14)\end{array}$ & 2.32 & $\begin{array}{l}484.46(452.28 \\
\text { to } 518.67)\end{array}$ & $\begin{array}{l}514.86(474.91 \\
\text { to } 558.86)\end{array}$ & 6.27 \\
\hline \multicolumn{10}{|l|}{ LICs } \\
\hline Male & $\begin{array}{l}61.50(44.10 \text { to } \\
80.97)\end{array}$ & $\begin{array}{l}81.40(58.54 \text { to } \\
108.12)\end{array}$ & 32.35 & $\begin{array}{l}834.31(734.05 \\
\text { to } 920.96)\end{array}$ & $\begin{array}{l}701.47(607.71 \\
\text { to } 807.96)\end{array}$ & -15.92 & $\begin{array}{l}895.81(795.47 \\
\text { to } 989.35)\end{array}$ & $\begin{array}{l}782.87(682.59 \\
\text { to } 899.47)\end{array}$ & -12.61 \\
\hline Female & $\begin{array}{l}77.61(56.39 \text { to } \\
101.50)\end{array}$ & $\begin{array}{l}97.51(71.57 \text { to } \\
126.69)\end{array}$ & 25.65 & $\begin{array}{l}641.19(540.91 \\
\text { to } 773.77)\end{array}$ & $\begin{array}{l}518.89(450.09 \\
\text { to } 600.83)\end{array}$ & -19.07 & $\begin{array}{l}718.80(614.24 \\
\text { to } 852.54)\end{array}$ & $\begin{array}{l}616.40(538.21 \\
\text { to } 704.61)\end{array}$ & -14.25 \\
\hline Both & $\begin{array}{l}69.97(50.87 \text { to } \\
91.78)\end{array}$ & $\begin{array}{l}89.95(65.58 \text { to } \\
117.75)\end{array}$ & 28.56 & $\begin{array}{l}732.18(651.61 \\
\text { to } 822.89)\end{array}$ & $\begin{array}{l}602.30(523.74 \\
\text { to } 689.61)\end{array}$ & -17.74 & $\begin{array}{l}802.15(716.50 \\
\text { to } 893.68)\end{array}$ & $\begin{array}{l}692.25(605.14 \\
\text { to } 785.67)\end{array}$ & -13.70 \\
\hline \multicolumn{10}{|l|}{$\begin{array}{l}\text { Lower } \\
\text { MICs }\end{array}$} \\
\hline Male & $\begin{array}{l}86.95(62.24 \text { to } \\
113.19)\end{array}$ & $\begin{array}{l}108.85(78.37 \\
\text { to } 142.55)\end{array}$ & 25.20 & $\begin{array}{l}630.85(565.26 \\
\text { to } 744.67)\end{array}$ & $\begin{array}{l}651.12(579.51 \\
\text { to } 739.73)\end{array}$ & 3.21 & $\begin{array}{l}717.80(650.34 \\
\text { to } 835.60)\end{array}$ & $\begin{array}{l}759.97(681.95 \\
\text { to } 856.46)\end{array}$ & 5.88 \\
\hline Female & $\begin{array}{l}97.80(70.30 \text { to } \\
127.70)\end{array}$ & $\begin{array}{l}123.26(88.95 \\
\text { to } 160.66)\end{array}$ & 26.04 & $\begin{array}{l}508.15(441.45 \\
\text { to } 572.10)\end{array}$ & $\begin{array}{l}491.88(423.51 \\
\text { to } 548.00)\end{array}$ & -3.20 & $\begin{array}{l}605.95(531.23 \\
\text { to } 677.46)\end{array}$ & $\begin{array}{l}615.15(541.46 \\
\text { to } 684.47)\end{array}$ & 1.52 \\
\hline Both & $\begin{array}{l}92.29(66.32 \text { to } \\
120.32)\end{array}$ & $\begin{array}{l}116.05(83.44 \\
\text { to } 151.12)\end{array}$ & 25.75 & $\begin{array}{l}567.85(514.72 \\
\text { to } 621.02)\end{array}$ & $\begin{array}{l}568.67(515.93 \\
\text { to } 621.51)\end{array}$ & 0.14 & $\begin{array}{l}660.14(601.55 \\
\text { to } 723.28)\end{array}$ & $\begin{array}{l}684.72(623.56 \\
\text { to } 746.12)\end{array}$ & 3.72 \\
\hline \multicolumn{10}{|l|}{$\begin{array}{l}\text { Upper } \\
\text { MICs }\end{array}$} \\
\hline Male & $\begin{array}{l}82.65(59.61 \text { to } \\
109.30)\end{array}$ & $\begin{array}{l}104.87(74.89 \\
\text { to } 140.33)\end{array}$ & 26.89 & $\begin{array}{l}417.83(381.07 \\
\text { to } 456.87)\end{array}$ & $\begin{array}{l}391.98(351.77 \\
\text { to } 433.27)\end{array}$ & -6.19 & $\begin{array}{l}500.48(456.39 \\
\text { to } 545.26)\end{array}$ & $\begin{array}{l}496.86(449.34 \\
\text { to } 551.52)\end{array}$ & -0.72 \\
\hline Female & $\begin{array}{l}95.10(68.56 \text { to } \\
124.85)\end{array}$ & $\begin{array}{l}116.28(83.74 \\
\text { to } 153.68)\end{array}$ & 22.28 & $\begin{array}{l}332.04(302.90 \\
\text { to } 362.72)\end{array}$ & $\begin{array}{l}291.19(261.08 \\
\text { to } 324.08)\end{array}$ & -12.30 & $\begin{array}{l}427.14(385.04 \\
\text { to } 470.83)\end{array}$ & $\begin{array}{l}407.47(361.69 \\
\text { to } 454.97)\end{array}$ & -4.61 \\
\hline Both & $\begin{array}{l}88.69(64.44 \text { to } \\
116.99)\end{array}$ & $\begin{array}{l}110.37(79.29 \\
\text { to } 146.64)\end{array}$ & 24.45 & $\begin{array}{l}369.16(344.16 \\
\text { to } 395.66)\end{array}$ & $\begin{array}{l}337.18(308.47 \\
\text { to } 366.80)\end{array}$ & -8.66 & $\begin{array}{l}457.84(419.92 \\
\text { to } 494.42)\end{array}$ & $\begin{array}{l}447.55(405.38 \\
\text { to } 493.01)\end{array}$ & -2.25 \\
\hline
\end{tabular}

In terms of gender, age-standardized YLD rate was higher in females than in males, whereas age-standardized rates of YLL and DALY of CKD were all higher in males than in females in globally and various income regions, (Table 2). Additionally, there were upward trends in the CKD-related age-specific YLD, YLL and DALY rates in various income regions, which were higher in aged $\geq 70$ years (Fig. 1).

Among all 137 LMICs, the highest age-standardized YLD, YLL and DALY rates of CKD in 2019 were seen in Mexico 296.40 per 100000 people (95\% UI: 206.99 to 394.46), Micronesia (Federated States of) 1895.00 per 100000 people (95\% UI: 1313.85 to 2478.01) and Micronesia (Federated States of) 2162.73 per 100 000 people (95\% Ul: 1584.61 to 2761.55), respectively. Whereas the lowest age-standardized YLD, YLL and DALY rates were seen in Ukraine 56.53 per 100000 people (95\% UI: 39.81 to 75.38), Belarus 69.79 per 100000 people (95\% UI: 55.13 to 89.34) and Belarus 128.92 per100 000 people (95\% UI: 104.56 to 156.45), respectively. From 1990 to 2019, the growth of age-standardized DALY rate varied from $-46.83 \%$ in Mongolia to $182.92 \%$ in El Salvador. The variations in other CKD burden metrics (YLDs, YLLs and DALYs) by country in 2019 can be found in Fig. 2 and Additional file.

There was much consistency in the PAF of CKD-related age-standardized DALYs for these risk factors in various income regions. In 2019, CKD-related risk factors with the top four PAF were kidney dysfunction, high systolic blood pressure, high fasting plasma glucose and high body-mass index, which all are metabolic risks (Fig. 3). The PAF of CKD-related age-standardized DALYs for risk factors in 2019 at the global level and by LMICs were presented in Table 3. 
Table 3

PAF (\%) of age-standardized DALYs for CKD risk factors in specific region, 1990-2019

\begin{tabular}{|c|c|c|c|}
\hline region & 1990PAF & 2019PAF & Percentage change in PAF, 1990-2019 \\
\hline \multicolumn{4}{|l|}{ Global } \\
\hline High temperature & $-0.07(-4.44$ to 2.70$)$ & $0.53(-1.52$ to 2.05$)$ & $-903.97(-1125.73$ to 1395.84$)$ \\
\hline Low temperature & $4.55(2.60$ to 6.43$)$ & $3.97(2.15$ to 5.60$)$ & $-12.71(-25.62$ to 1.70$)$ \\
\hline Lead exposure & $3.16(1.90$ to 4.63$)$ & $2.92(1.70$ to 4.33$)$ & $-7.60(-13.74$ to -3.33$)$ \\
\hline Diet high in sodium & $6.65(2.12$ to 13.92$)$ & $6.11(1.50$ to 13.95$)$ & $-8.20(-34.98$ to 1.56$)$ \\
\hline High fasting plasma glucose & $29.15(24.92$ to 33.18$)$ & $30.89(26.49$ to 34.95$)$ & $5.99(1.48$ to 9.25$)$ \\
\hline High systolic blood pressure & $47.48(42.63$ to 52.14$)$ & $51.36(45.96$ to 56.42$)$ & $8.17(4.17$ to 11.30$)$ \\
\hline High body-mass index & $15.80(8.35$ to 25.53$)$ & $26.46(16.69$ to 37.46$)$ & $67.48(42.97$ to 105.85$)$ \\
\hline Kidney dysfunction & 100.00 & 100.00 & 0.00 \\
\hline \multicolumn{4}{|l|}{ LICs } \\
\hline High temperature & $-0.02(-7.62$ to 4.55$)$ & $0.63(-3.67$ to 2.40$)$ & $-3026.12(-877.52$ to 676.46$)$ \\
\hline Low temperature & $3.71(1.90$ to 5.38$)$ & $3.24(1.46$ to 4.93$)$ & $-12.62(-26.55$ to 5.47$)$ \\
\hline Lead exposure & $3.66(2.29$ to 5.20$)$ & $3.73(2.34$ to 5.24$)$ & $1.73(-6.07$ to 8.71$)$ \\
\hline Diet high in sodium & $5.71(0.86$ to 15.00$)$ & $4.92(0.48$ to 14.20$)$ & $-13.83(-51.75$ to -1.40$)$ \\
\hline High fasting plasma glucose & $28.49(23.32$ to 33.25$)$ & $29.15(24.25$ to 33.42$)$ & $2.31(-2.66$ to 6.55$)$ \\
\hline High systolic blood pressure & $48.85(43.66$ to 54.11$)$ & $52.62(47.37$ to 57.61$)$ & $7.72(0.82$ to 11.89$)$ \\
\hline High body-mass index & $10.94(4.62$ to 20.08$)$ & $18.64(10.40$ to 28.84$)$ & $70.37(40.14$ to 133.32$)$ \\
\hline Kidney dysfunction & 100.00 & 100.00 & 0.00 \\
\hline \multicolumn{4}{|l|}{ Lower MICs } \\
\hline High temperature & $-0.14(-8.82$ to 5.31$)$ & $0.90(-2.38$ to 3.56$)$ & $-729.61(-1321.80$ to 1093.38$)$ \\
\hline Low temperature & $2.59(0.50$ to 4.49$)$ & $2.56(0.23$ to 4.52$)$ & $-1.32(-50.39$ to 36.88$)$ \\
\hline Lead exposure & $4.20(2.79$ to 5.79$)$ & $3.97(2.60$ to 5.50$)$ & $-5.35(-11.02$ to -0.82$)$ \\
\hline Diet high in sodium & $5.15(0.98$ to 12.41$)$ & $4.97(0.62$ to 12.68$)$ & $-3.53(-39.12$ to 4.48$)$ \\
\hline High fasting plasma glucose & $30.02(25.17$ to 34.53$)$ & $32.52(27.66$ to 37.00$)$ & $8.33(3.62$ to 12.33$)$ \\
\hline High systolic blood pressure & $48.13(43.14$ to 53.29$)$ & $51.82(46.08$ to 57.17$)$ & $7.66(2.87$ to 11.00$)$ \\
\hline High body-mass index & $11.18(5.19$ to 19.70$)$ & $23.68(14.51$ to 34.14$)$ & $111.83(66.28$ to 196.48$)$ \\
\hline Kidney dysfunction & 100.00 & 100.00 & 0.00 \\
\hline \multicolumn{4}{|l|}{ Upper MICs } \\
\hline High temperature & $-0.03(-1.47$ to 0.82$)$ & $0.21(-0.67$ to 0.77$)$ & $-858.03(-1391.68$ to 1289.47$)$ \\
\hline Low temperature & $5.83(3.17$ to 8.40$)$ & $4.79(2.78$ to 6.75$)$ & $-17.73(-26.50$ to -3.66$)$ \\
\hline Lead exposure & $3.07(1.82$ to 4.52$)$ & $2.90(1.67$ to 4.37$)$ & $-5.67(-11.73$ to -0.70$)$ \\
\hline Diet high in sodium & $9.49(3.90$ to 17.23$)$ & $8.74(3.05$ to 17.12$)$ & $-7.83(-30.95$ to 5.14$)$ \\
\hline High fasting plasma glucose & $31.37(27.18$ to 35.03$)$ & $31.79(27.68$ to 35.63$)$ & $1.35(-2.72$ to 5.80$)$ \\
\hline High systolic blood pressure & $45.87(40.97$ to 50.79$)$ & $53.64(48.10$ to 59.04$)$ & $16.94(12.55$ to 22.01$)$ \\
\hline High body-mass index & $16.71(8.67$ to 27.05$)$ & $29.01(18.14$ to 41.21$)$ & $73.58(48.84$ to 113.01$)$ \\
\hline Kidney dysfunction & 100.00 & 100.00 & 0.00 \\
\hline
\end{tabular}

From 1990 to 2019, there were upward trends in the PAF contributions of high fasting plasma glucose, high systolic blood pressure, and high body-mass index to age-standardized CKD DALYs in various income regions (Table 3). Notably, the greatest increase in the PAF attributed to high body-mass in various income regions, especially in Lower MICs (111.83\% (95\% Ul: 66.28 to 196.48)), followed by Upper MICs (73.58\% (95\% UI: 48.84 to 113.01)) and LICs (70.37\% (95\% Ul: 40.14 to 133.32)). In addition, the PAF of age-standardized DALYs for high systolic blood pressure increased significantly in Upper MICs than in LICs and Lower MICs (Fig. 4).

\section{Discussion}


Chronic kidney disease (CKD) is a significant global health problem and one of the top 20 causes of death worldwide. It is a serious threat to people's life and health[20, 21]. CKD DALYs is calculated by adding the YLLs and the YLDs, we found that the age-standardized YLL rate is much higher than the YLD rate at the global level and in various income regions, suggesting that premature death is the main cause of CKD burden. The age-standardized YLD rates all showed an upward trend in LICs, Lower MICs and Upper MICs, the age-standardized YLL rates decreased in LICs, Upper MICs and demonstrated a minor increase trend in Lower MICs, suggesting that future CKD treatment strategies should focus on improving the quality of life of CKD patients.

Our results show disparities in CKD burden were also observed in geographical regions and countries. LICs had the highest age-standardized DALY rate, followed by Lower MICs, which may be related to different exposures to risk factors, weak health systems, inadequate health care funding, access to effective health care interventions[22]. These findings call for increased planning and interventions,and developed novel and more appropriate solutions to address the burden of CKD in these areas[23]. The greatest decline in age-standardized DALY rates of CKD were all seen in LICs. This may be related to the improvement of medical technology and effective health care reform. However, the age-standardized DALY rate showed an upward trend in Lower MICs in 2019. If these trends continue, the disparities that exist in CKD burden between Lower MICs and LICs and Upper MICs will be further increased.

Furthermore, our results showed that The CKD burden showed homogeneity by gender among global and LMICs: age-standardized YLD rate was higher in females than in males, whereas age-standardized rates of YLL and DALY of CKD were all higher in males than in females. The disease burden of CKD is mainly due to premature death in males and disability in females. This difference may be related to physiological differences, estrogen levels and lifestyle between males and females[24]. This gender difference should also be taken into account by policy makers when planning future strategies and implementing preventive and control measures. Additionally, there were upward trends in the CKD-related age-specific YLD, YLL and DALY rates in various income regions, which were higher in aged $\geq 70$ years, speculated this change is largely related to the aging population and the increase of the elderly population. More attention should be paid to the elderly in the prevention and treatment of CKD.

In 2019, except for age and other non-modifiable risk factors, kidney dysfunction, high systolic blood pressure, high fasting plasma glucose, and high bodymass index remained the major causes attributable age-standardized CKD DALYs in LMICs. Unfortunately, there was no remarkable decline in PAF of them since 1990. This may be related to the increased incidence and prevalence of hypertension, dyslipidemia, overweight and obesity and sedentary lifestyle in the population over the past 30 years[25]. Therefore, more efforts are needed to create healthy lifestyles. Moreover, there were upward trends in the PAF of DALYs contributions of high systolic blood pressure, high fasting plasma glucose, and high body-mass in LMICs from 1990 to 2019 . Perhaps most concerning are high body mass index, especially in Lower MICs, so it is imperative that effective measures be taken to curb the rise of obesity. There is clear evidence that interventions to manage hypertension and promote weight loss are associated with reduced risks of developing CKD and better outcomes among those living with CKD[26-28]. Therefore, it is important to develop relevant strategies and targeted measures to prevent and manage hypertension, diabetes, and obesity.

\section{Limitations}

Our study has several limitations. First, since data for this study is part of GBD 2019 study, all limitations of the GBD 2019 methods outlined elsewhere also apply here[7, 8]. In the estimation of YLDs, the disability weight is derived from statistical data of multiple countries around the world, which is uncertainty in the estimation of disease in LMICs. In addition, a comprehensive assessment of the burden of disease should also include the economic, family and social aspects of the burden, so a multi-dimensional analysis can be considered to improve the accuracy of the results[29].

\section{Conclusions}

This study has evaluated the burden of CKD and its risk-attributable burden in 137 LMICs from 1990 to 2019. CKD burden remains high in various income regions, especially in MICs and Lower MICs. More effective and targeted preventive policies and interventions aimed at mitigating preventable CKD burden and addressing risk factors are urgently needed, particularly in geographies with high or increasing burden.

\section{Abbreviations}

\section{GBD}

Global Burden of Disease

CKD

Chronic kidney disease

LMICs

Low - and middle-income countries

MICs

Low-income countries

Lower MICs

Lower-middle income countries

Upper MICs

Upper-middle income countries

YLD

Years lived with disability

YLL

Years of life lost

DALY 
Disability-adjusted life-years

PAF

Population-attributable faction

UI

Uncertainty interval

\section{Declarations}

\section{Ethics approval and consent to participate}

Not applicable

\section{Consent for publication}

Not applicable

Availability of data and materials

Data for this study were obtained from the GBD 2019 study. This study adherence to the Guidelines for Accurate and Transparent Health Estimates Reporting (GATHER) recommendations. All data used in this study were obtained from the Institute for Health Metrics and Evaluation (IHME) website(http://ghdx.healthdata.org/gbd-results-tool)[15]. And the public access to the database is open.

\section{Competing interests}

None of the authors have any conflicts of interests to declare.

\section{Funding}

This study was supported by the National Natural Science Foundation of China (81872721); National Key R\&D Program of China (2017YFC1310902). The funding body of this research had no role in the design of the study and collection, analysis, and interpretation of data and in writing the manuscript.

\section{Author information}

\section{Affiliations}

School of Public Health and Management, Weifang Medical University, Weifang 261053, China

Changrong Ke, Juanjuan Liang, Mi Liu, Chunping Wang

Chinese Center for Disease Control and Prevention, Beijing 102206, China

Shiwei Liu

\section{Authors' contributions}

$\mathrm{CK}, \mathrm{SL}$ and $\mathrm{CW}$ conceived the study. CK, JL and ML analyzed and interpreted data on the disease burden of CKD. CK, JL and ML wrote the paper. SL and CW guided the writing of the paper. All authors read and approved the final manuscript.

\section{Corresponding authors}

Correspondence to Chunping Wang

\section{Acknowledgements}

The authors would like to thank all members of the Institute for Health Metrics and Evaluation (IHME), and all collaborators involved in GBD 2019 study.

\section{References}

1. Levey AS, Atkins R, Coresh J, Cohen EP, Collins AJ, Eckardt KU, Nahas ME, Jaber BL, Jadoul M, Levin A et al: Chronic kidney disease as a global public health problem: approaches and initiatives - a position statement from Kidney Disease Improving Global Outcomes. Kidney Int 2007, 72(3):247-259.

2. Bikbov. B, Purcell. C, Levey. AS, Smith. M, Abdoli. A, Abebe M, Adebayo. OM, Afarideh. M, Agarwal. SK, Agudelo-Botero. M et al: Global, regional, and national burden of chronic kidney disease, 1990-2017: a systematic analysis for the Global Burden of Disease Study 2017. Lancet (London, England) 2020, 395(10225):709-733.

3. Sarnak MJ, Levey AS, Schoolwerth AC, Coresh J, Culleton B, Hamm LL, McCullough PA, Kasiske BL, Kelepouris E, Klag MJ et al: Kidney disease as a risk factor for development of cardiovascular disease: a statement from the American Heart Association Councils on Kidney in Cardiovascular Disease, High Blood Pressure Research, Clinical Cardiology, and Epidemiology and Prevention. Hypertension (Dallas, Tex : 1979) 2003, 42(5):1050-1065. 
4. Li PK, Garcia-Garcia G, Lui SF, Andreoli S, Fung WW, Hradsky A, Kumaraswami L, Liakopoulos V, Rakhimova Z, Saadi G et al: Kidney health for everyone everywhere-from prevention to detection and equitable access to care. Pediatr Nephrol 2020, 35(10):1801-1810.

5. Foreman KJ, Marquez N, Dolgert A, Fukutaki K, Fullman N, McGaughey M, Pletcher MA, Smith AE, Tang K, Yuan CW et al: Forecasting life expectancy, years of life lost, and all-cause and cause-specific mortality for 250 causes of death: reference and alternative scenarios for 2016-40 for 195 countries and territories. Lancet (London, England) 2018, 392(10159):2052-2090.

6. Stanifer JW, Muiru A, Jafar TH, Patel UD: Chronic kidney disease in low- and middle-income countries. Nephrology, dialysis, transplantation : official publication of the European Dialysis and Transplant Association - European Renal Association 2016, 31(6):868-874.

7. Murray CJL, Aravkin AY, Zheng P, Abbafati C, Abbas KM, Abbasi-Kangevari M, Abd-Allah F, Abdelalim A, Abdollahi M, Abdollahpour I et al: Global burden of 87 risk factors in 204 countries and territories, 1990-2019: a systematic analysis for the Global Burden of Disease Study 2019. The Lancet 2020, 396(10258):1223-1249

8. Vos T, Lim SS, Abbafati C, Abbas KM, Abbasi M, Abbasifard M, Abbasi-Kangevari M, Abbastabar H, Abd-Allah F, Abdelalim A et al: Global burden of 369 diseases and injuries in 204 countries and territories, 1990-2019: a systematic analysis for the Global Burden of Disease Study 2019. The Lancet 2020, 396(10258):1204-1222

9. Murray CJ, Lopez AD: Global mortality, disability, and the contribution of risk factors: Global Burden of Disease Study. Lancet (London, England) 1997, 349(9063):1436-1442.

10. Murray CJ, Ezzati M, Lopez AD, Rodgers A, Hoorn4 SV: Comparative quantification of health risks conceptual framework and methodological issues. Popul Health Metr 2003, 1:1.

11. Gakidou. E, Afshin. A, Abajobir. AA, Abate. KH, Abbafati. C, Abbas. KM, Abd-Allah. F, Abdulle. AM, Abera. SF, Aboyans. V et al: Global, regional, and national comparative risk assessment of $\mathbf{8 4}$ behavioural, environmental and occupational, and metabolic risks or clusters of risks, 1990-2016: a systematic analysis for the Global Burden of Disease Study 2016. Lancet (London, England) 2017, 390(10100):1345-1422.

12. Stanaway. JD, Afshin. A, Gakidou. E, Lim. SS, Abate. D, Abate. KH, Abbafati. C, Abbasi. N, Abbastabar. H, Abd-Allah. F et al: Global, regional, and national comparative risk assessment of $\mathbf{8 4}$ behavioural, environmental and occupational, and metabolic risks or clusters of risks for 195 countries and territories, 1990-2017: a systematic analysis for the Global Burden of Disease Study 2017. Lancet (London, England) 2018, 392(10159):1923-1994.

13. James. SL, Abate. D, Abate. KH, Abay. SM, Abbafati. C, Abbasi. N, Abbastabar. H, Abd-Allah. F, Abdela. J, Abdelalim. A et al: Global, regional, and national incidence, prevalence, and years lived with disability for 354 diseases and injuries for 195 countries and territories, 1990-2017: a systematic analysis for the Global Burden of Disease Study 2017. Lancet (London, England) 2018, 392(10159):1789-1858.

14. Stevens GA, Alkema L, Black RE, Boerma JT, Collins GS, Ezzati M, Grove JT, Hogan DR, Hogan MC, Horton R et al: Guidelines for Accurate and Transparent Health Estimates Reporting: the GATHER statement. Lancet (London, England) 2016, 388(10062):e19-e23.

15. GBD results tool Institute for Health Metrics and Evaluation (IHME). GBD results tool. http://ghdx.healthdata.org/gbd-results-tool. (accessed Mar 20, 2021)

16. Fraser SDS, Roderick PJ: Kidney disease in the Global Burden of Disease Study 2017. Nature reviews Nephrology 2019, 15(4):193-194.

17. Bikbov. B, Purcell. CA, Levey. AS, Smith. M, Abdoli. A, Abebe. M, Adebayo. OM, Afarideh. M, Agarwal. SK, Agudelo-Botero. M et al: Global, regional, and national disability-adjusted life-years (DALYs) for 359 diseases and injuries and healthy life expectancy (HALE) for 195 countries and territories, 1990 2017: a systematic analysis for the Global Burden of Disease Study 2017. Lancet (London, England) 2018, 392(10159):1859-1922.

18. Liu S, Li Y, Zeng X, Wang H, Yin P, Wang L, Liu Y, Liu J, Qi J, Ran S et al: Burden of Cardiovascular Diseases in China, 1990-2016: Findings From the 2016 Global Burden of Disease Study. JAMA cardiology 2019, 4(4):342-352.

19. Kyu HH, Abate D, Abate KH, Abay SM, Abbafati C, Abbasi N, Abbastabar H, Abd-Allah F, Abdela J, Abdelalim A et al: Global, regional, and national disability-adjusted life-years (DALYs) for 359 diseases and injuries and healthy life expectancy (HALE) for 195 countries and territories, 1990-2017: a systematic analysis for the Global Burden of Disease Study 2017. The Lancet 2018, 392(10159):1859-1922.

20. Bradshaw C, Kondal D, Montez-Rath ME, Han J, Zheng Y, Shivashankar R, Gupta R, Srinivasapura Venkateshmurthy N, Jarhyan P, Mohan S et al: Early detection of chronic kidney disease in low-income and middle-income countries: development and validation of a point-of-care screening strategy for India. BMJ Glob Health 2019, 4(5):e001644.

21. Roth GA, Abate D, Abate KH, Abay SM, Abbafati C, Abbasi N, Abbastabar H, Abd-Allah F, Abdela J, Abdelalim A et al: Global, regional, and national age-sexspecific mortality for 282 causes of death in 195 countries and territories, 1980-2017: a systematic analysis for the Global Burden of Disease Study 2017. The Lancet 2018, 392(10159):1736-1788.

22. Ameh OI, Ekrikpo UE, Kengne AP: Preventing CKD in Low- and Middle-Income Countries: A Call for Urgent Action. Kidney Int Rep 2020, 5(3):255-262.

23. Li PK, Garcia-Garcia G, Lui SF, Andreoli S, Fung WW, Hradsky A, Kumaraswami L, Liakopoulos V, Rakhimova Z, Saadi G et al: Kidney Health for Everyone Everywhere-From Prevention to Detection and Equitable Access to Care. J Ren Care 2020, 46(1):4-12.

24. JH L: Gender difference of death and disease burden among residents in Chengyang District of Qingdao. Shandong University; 2014.

25. Zhao. Y, Yan. H, Marshall. RJ, Dang. S, Yang. R, Li. Q, Qin X: pressure and prevalence, awareness, treatment, and control of hypertension among middleaged and older adults in a rural area of Northwest China from 1982 to 2010. PLoS One 2013, 8(4):e61779.

26. Luyckx VA, Tuttle KR, Garcia-Garcia G, Gharbi MB, Heerspink HJL, Johnson DW, Liu ZH, Massy ZA, Moe O, Nelson RG et al: Reducing major risk factors for chronic kidney disease. Kidney Int Suppl (2011) 2017, 7(2):71-87.

27. Stenvinkel P, Zoccali C, Ikizler TA: Obesity in CKD-what should nephrologists know? J Am Soc Nephro/ 2013, 24(11):1727-1736.

28. Jun M, Hemmelgarn BR: Strategies for BP Control in Developing Countries and Effects on Kidney Function. Clin J Am Soc Nephrol 2016, 11(6):932-934. 
29. Fu-zhen. W, Ya-li. Q, Hui. L: The methodological development of disease burden's research - comprehensive evaluation of disease burden. Chinese Journal of Disease Control 2003, 7(6):537-539.

\section{Figures}
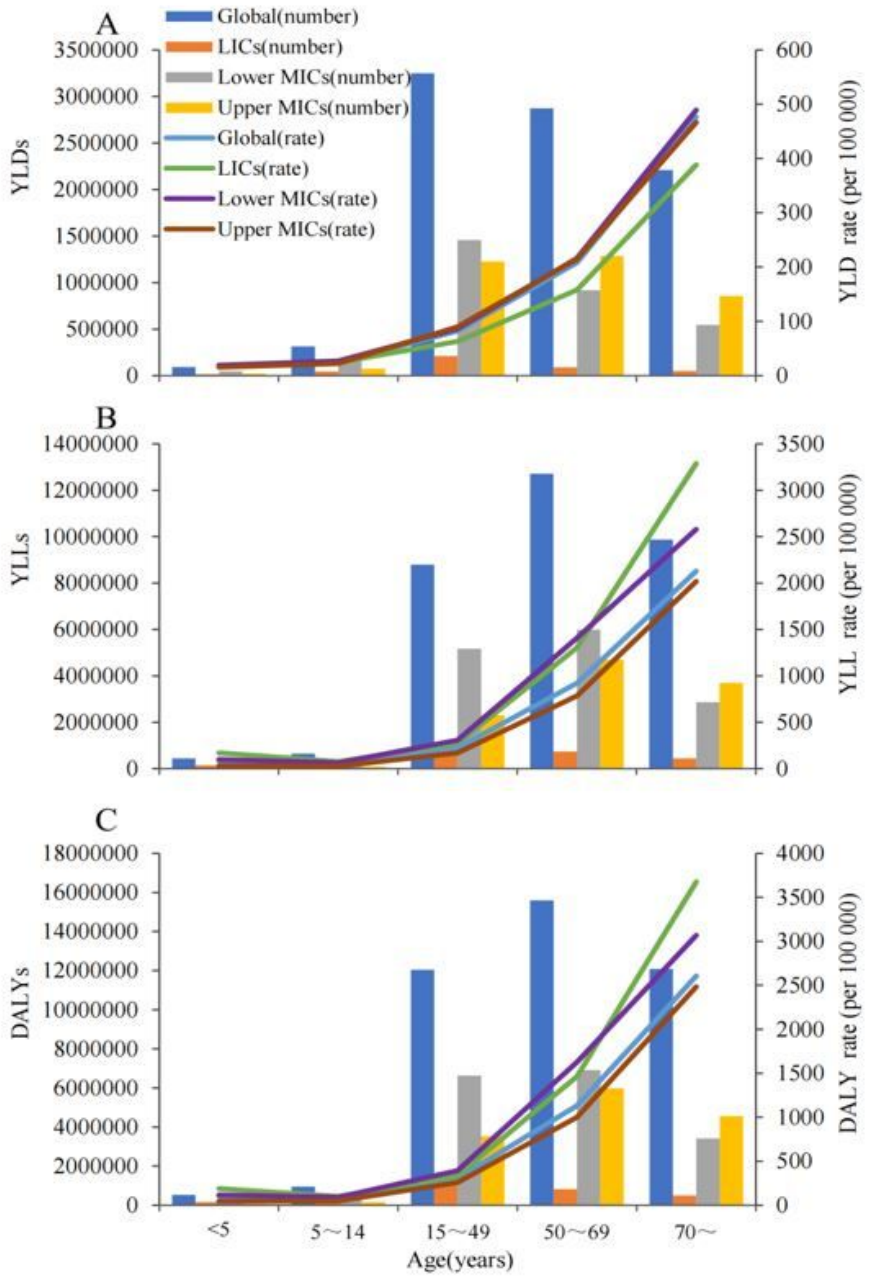

\section{Figure 1}

Age-specific numbers and rates of YLDs (A) $\triangle$ YLLs (B) and DALYs (C) of CKD , 2019 

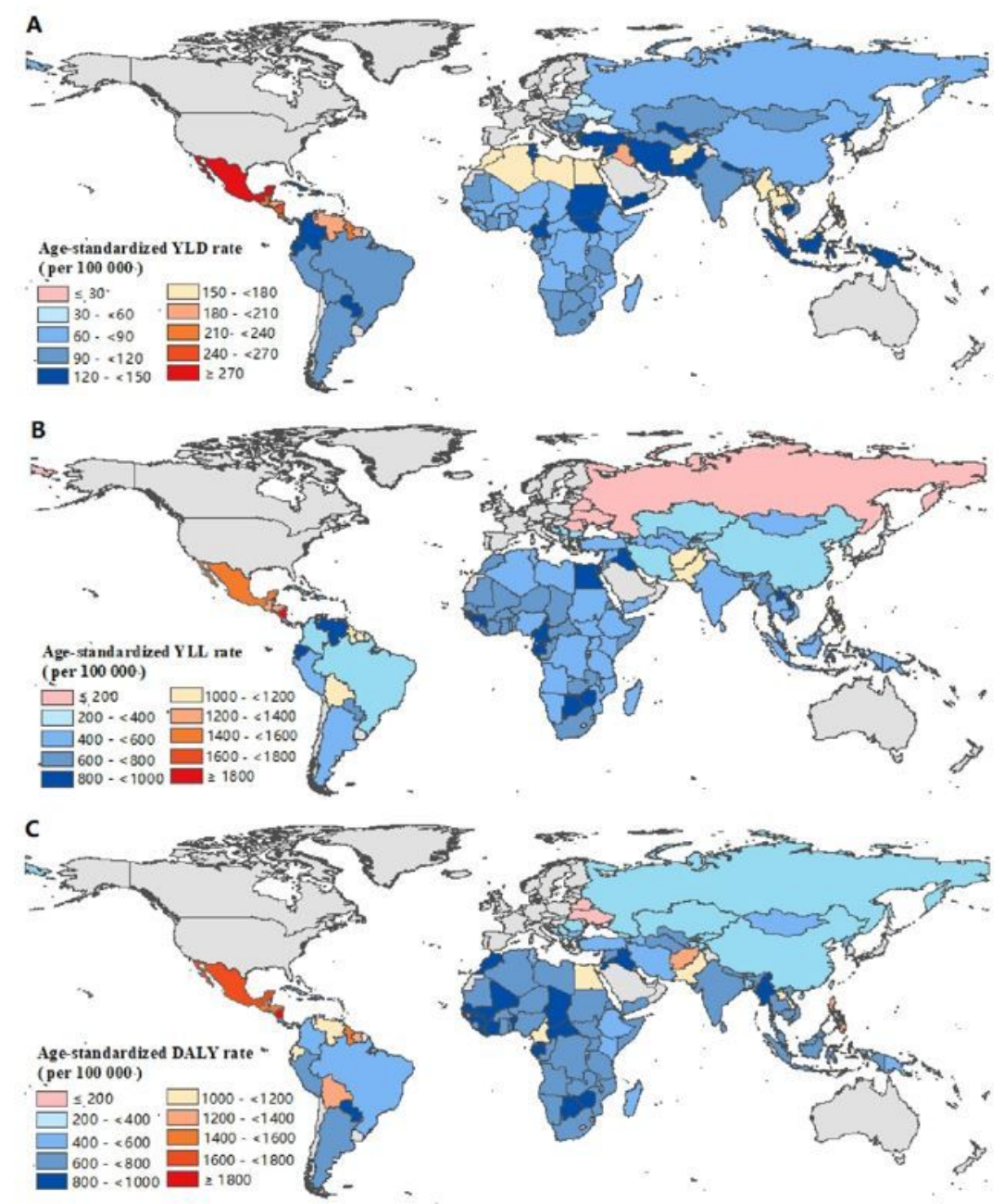

Figure 2

Age-standardized YLD (A), YLL (B) and DALY (C) rates of CKD across 137 low-and middle-income countries, 2019.

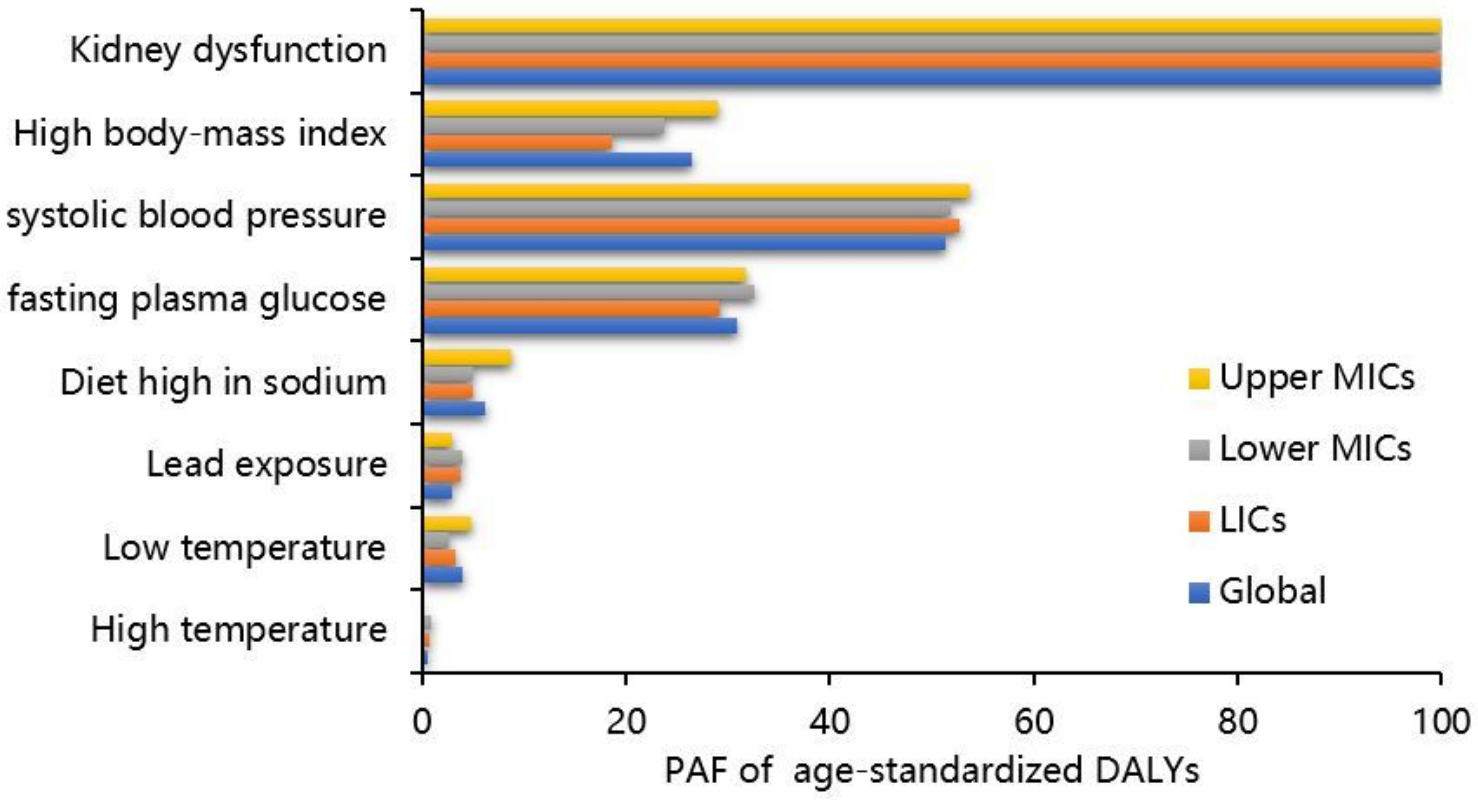

Figure 3 


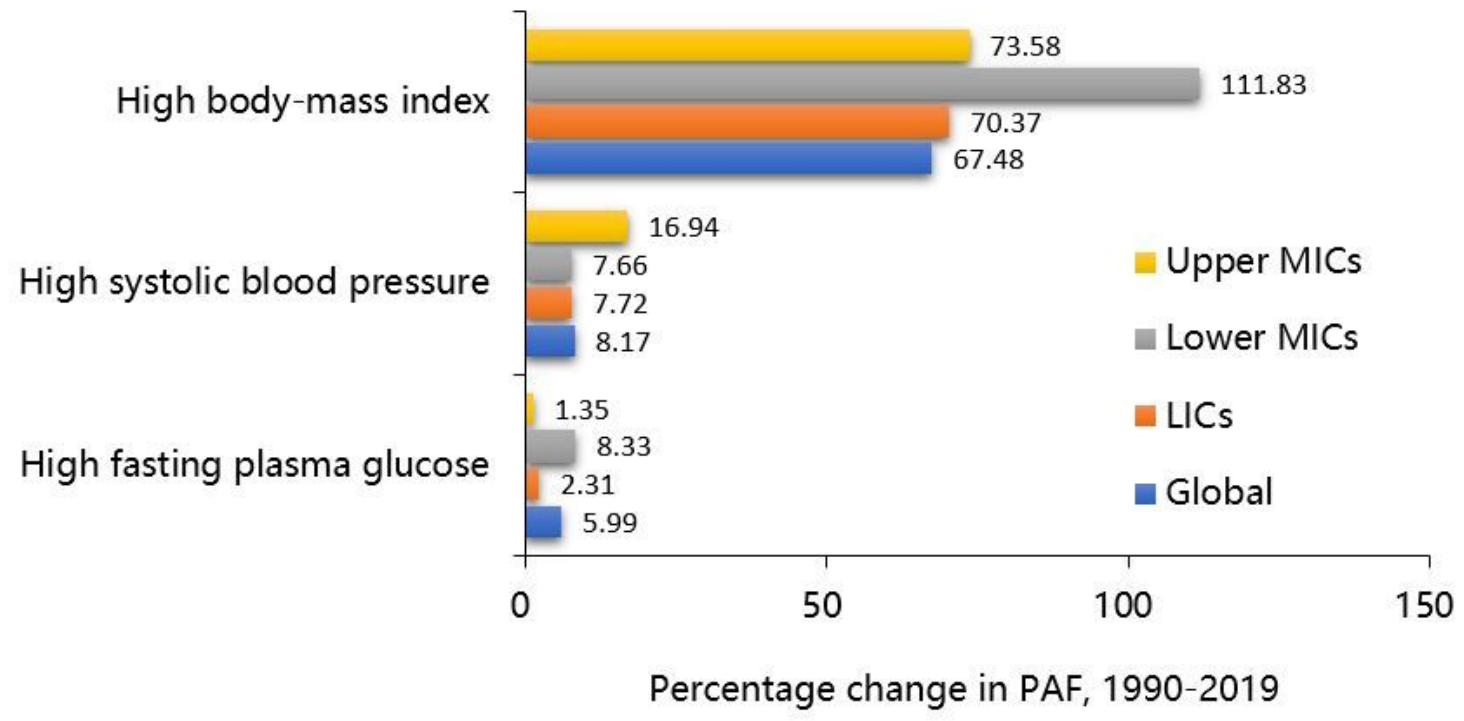

Figure 4

Percentage change (\%) in PAF contributions of major risk factors of CKD in specific region, 1990-2019

\section{Supplementary Files}

This is a list of supplementary files associated with this preprint. Click to download.

- Additionalfile.docx 